\title{
A clinical study of cytokine-induced killer cells for the treatment of refractory lymphoma
}

\author{
ZHI GUO*, HAO LIU*, XUE-PENG HE, XIAO-HUA TAN, YAN ZHOU, \\ XIA CHEN, YU-JIE SHI, XIAO-DONG LIU and HUI-REN CHEN \\ Department of Hematology, Beijing Military General Hospital, The Affiliated \\ Hospital of Anhui Medical University, Beijing, P.R. China
}

Received November 2, 2010; Accepted February 28, 2011

DOI: $10.3892 / 01.2011 .269$

\begin{abstract}
Cytokine-induced killer (CIK) cell therapy, an adoptive T-cell immunotherapy, has been reported to be a safe and effective mode of treatment for patients with metastatic diseases, lymphoma and acute leukaemia. To investigate the clinical efficacy of cytokine-induced killer cells for the treatment of refractory lymphoma, the present clinical study was conducted. A total of 8 male patients with a mean age of 41 years (range 22-65) who were pathologically diagnosed with malignant lymphoma (Hodgkin's disease, 2 and non-Hodgkin's lymphoma, 6) were enrolled. CIK cells were expanded by priming with IFN- $\gamma$, monoclonal antibody (mAb) to CD3 and IL- $1 \alpha$, followed by the addition of IL- 2 the following day using peripheral blood mononuclear cells (PBMCs) of the 8 male patients. The CIK cells were then transfused back to the patients as treatment. On day 13 , the CIK cell count reached $7-18 \times 10^{19}\left(\right.$ mean, $\left.12.7 \times 10^{9}\right)$, a 44 - to 140 -fold increase (mean, 98-fold). The average percentage of cells expressing $\mathrm{CD}^{+}, \mathrm{CD}^{+}, \mathrm{CD}^{+}$and $\mathrm{CD}^{+}{ }^{+} \mathrm{CD} 56^{+}$were also increased from $50.9 \pm 3.5,29.9 \pm 1.7,41.3 \pm 3.2,1.6 \pm 0.2 \%$ to $90.2 \pm 1.6,40.6 \pm 5.5$, $52.8 \pm 4.9$ and $33.1 \pm 4.0 \%$, respectively. Patients showed measurable radiographic tumor reduction, increased T-cell subset levels, and relief of symptoms after treatment. No severe toxicity or side effects were reported. CIK cells developed by this culture method have a high in vitro proliferation rate and tumor-killing capacity. In conclusion, CIK cell treatment of patients with malignant lymphoma achieves effective clinical responses, causing few side effects.
\end{abstract}

Correspondence to: Dr Zhi Guo, Department of Hematology, Beijing Military General Hospital, Dongcheng, Beijing 100700, P.R. China E-mail: 1hgz2010@yahoo.com.cn

*Contributed equally

Key words: cytokine-induced killer cells, malignant lymphoma, adoptive immune therapy

\section{Introduction}

High-dose chemotherapy with autologous hematopoietic stem cell transplantation has been the cornerstone of salvage therapy for patients with relapsed or refractory lymphoid malignancies. However, this method has limited applications. Recently, alternative treatment strategies such as immunotherapeutic interventions, which activate autologous effector cells to identify and kill tumor targets have been explored.

Cytokine-induced killer (CIK) cell therapy, a novel T-cell adoptive immunotherapy, was first introduced by SchmidtWolf et al, in 1991, where CIK cells were developed by growing peripheral blood mononuclear cells in the presence of interferon (IFN)- $\gamma$, anti-CD3 mAb, and interleukin (IL)-2 (1). Since then, the development of CIK cell adoptive immunotherapy for the treatment of malignant diseases has received considerable attention. CIK cells are ex vivo activated and expanded $\mathrm{CD}^{+}$natural killer $\mathrm{T}$ cells that have been shown to have anti-tumor activity $(2,3)$. CIK cells are thought to have high cytotoxic activity against lymphoma cells, while exhibiting little toxicity against a subset of normal human hematopoietic precursor cells. Preclinical studies have shown that the adoptive transfer of CIK cells significantly reduces tumor burden and improves survival in hematological malignancies and solid tumors in mouse models (4). In clinical studies, autologous CIK cell therapy was found to ameliorate the symptoms of patients with primary hepatocellular carcinoma, rhabdomyosarcoma and renal cancer, and no severe side effects were found (5-7). CIK cells have been found to reduce acquisition of homing molecules required for the entry of cells into inflamed graft-versus-host disease (GVHD) target organs, causing GVHD (8). CIK cells can also be an alternative to bulk donor lymphocyte infusion (DLI) (9).

In a previous study, the culture method for cytokineinduced killer cells was investigated using CD3 mAb, IL-2, IFN- $\gamma$ and IL-1 $\alpha$ in vitro (3). Results of that study showed that CIK cells developed by PMBCs, collected from patients with refractory lymphoma, possessed the ability to achieve a high proliferation rate, and the immunophenotype of the cells indicated strong antitumor activities.

In this study, CIK cells were developed under good manufacturin practice (GMP) laboratory conditions and were transfused back to the patients for treatment. The CIK cell 


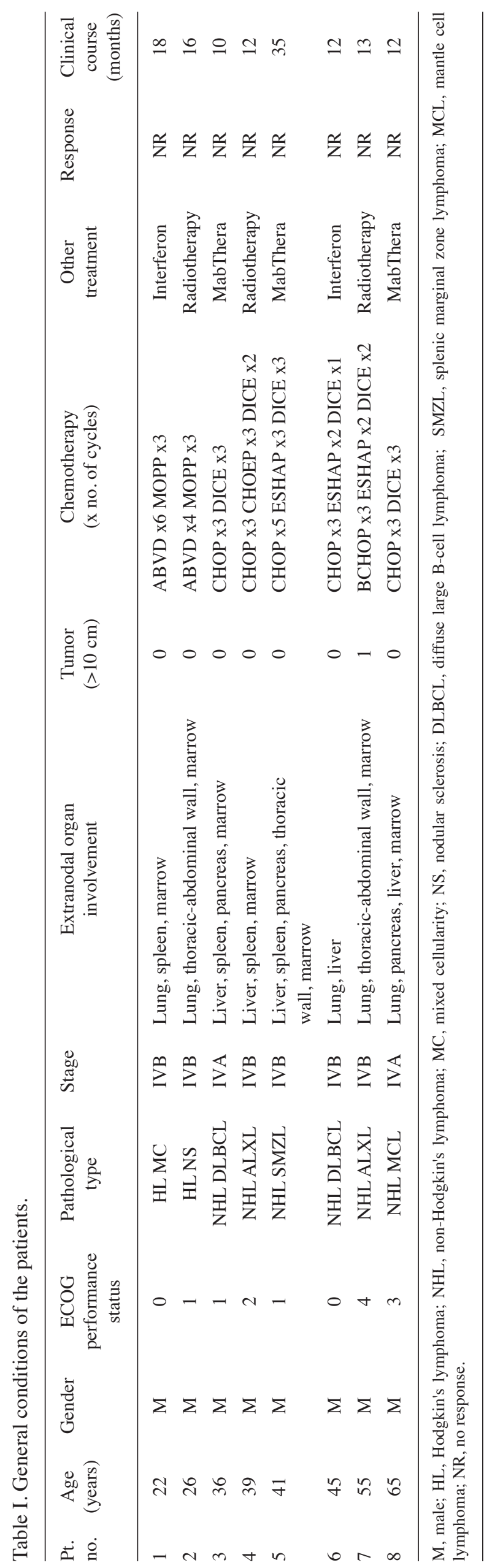

count and phenotype was investigated, and the clinical efficacy on patients was also measured.

\section{Materials and methods}

Patients. A total of 8 male patients with a mean age of 41 years (range 22-65), who were pathologically diagnosed with malignant lymphoma (Hodgkin's disease, 2 and non-Hodgkin's lymphoma, 6) and admitted to the Beijing Military Hospital from September 2006 to December 2009, were treated. The patients signed an informed consent approved by the Beijing Ethics Commission. Patients had involvement of at least 2-3 extranodal organs at onset. ABVD, CHOP, MINI, ESHAP, DICE and VIP chemotherapy for 6-10 cycles were administered without remission (Table I).

Peripheral blood mononuclear cell collection and separation. Peripheral blood (5-6 1) of each patient was circulated, and 50-100 ml peripheral blood mononuclear cell (PBMCs) concentrates were collected using a CS3000 Plus blood cell separator. We purified the PBMC concentrates with equal amounts of Ficoll-Paque Plus, centrifuged at 2,000 rpm for $20 \mathrm{~min}$ at room temperature, and then mixed with sterile saline, centrifuged at $1,500 \mathrm{rpm}$ for $5 \mathrm{~min}$ at $4^{\circ} \mathrm{C}$.

CIK cell culture and count. Subject to GMP laboratory conditions, 0.6-1.2 $\times 10^{10} \mathrm{PBMCs}$ were obtained from each patient and among these $1-2 \times 10^{8} \mathrm{CD} 3{ }^{+} \mathrm{CD}^{2} 6^{+}$were effector cells. PBMC concentrates were cultured in $10 \% \mathrm{AB}$ serum/RPMI1640 with a cell concentration of $1-3 \times 10^{6} / \mathrm{ml}$ at $37^{\circ} \mathrm{C}$ and $5 \%$ $\mathrm{CO}_{2}$ in culture bags. Anti-CD3 mAb (100 ng/ml), recombinant human IL-1 $\alpha(100 \mathrm{U} / \mathrm{ml})$ and recombinant human IFN- $\gamma$ $(1,000 \mathrm{U} / \mathrm{ml})$ were added on day 1 . Recombinant human IL-2 (300 U/ml) was added on day 2. Culture solution was changed every 3 days, and recombinant IL-2 and recombinant IFN- $\gamma$ were added to maintain its concentration. The cell survival rate was evaluated by trypan blue staining on days $1,4,7,10$ and 13 of culture. In accordance with the ideal conditions for adoptive cellular immunotherapy, after 10-13 days, with cell viability $>70 \%, \mathrm{CD}^{+} \mathrm{CD}^{2} 6^{+} \mathrm{NKT}>30 \%, \mathrm{CD}^{+} \mathrm{CD}^{+} \mathrm{T}$ cells $>30 \%$, bacterial and fungal cultures negative, the cells were subsequently harvested.

CIK cell phenotype analysis. Phenotypic analysis of the CIK cells was achieved by using fluorescein-labeled monoclonal antibodies to $\mathrm{CD}^{+}$and $\mathrm{CD}^{+} 6^{+}$and phycoerythrin-labeled antibodies to $\mathrm{CD}^{2} 6^{+}, \mathrm{CD} 4^{+}$and $\mathrm{CD} 8^{+}$. Cells were incubated with antibodies for $30 \mathrm{~min}$ at $4^{\circ} \mathrm{C}$. The immunophenotype of the PBMCs was also analyzed as a comparison.

CIK cell transfusion. The CIK cells were diluted with $100 \mathrm{ml}$ saline and transfused back to the patients, $1 / 3$ to 4 fractions at a time, once every 2-3 days. The cell count at each transfusion was $>10^{9}$. Deproteinized nutrition cell extract of calf blood and $>2,000 \mathrm{ml}$ fluid were administered following transfusion.

CIK cell treatment. During every course of treatment, CIK cells were infused 2-5 times. Each time the number of infused cells was not $<10^{9}$, and the total number of cells per 
Table II. $\mathrm{CD}^{+}{ }^{+} \mathrm{CD} 56^{+}$effector cell count $\left(\mathrm{x} 10^{8}\right)$ at different culture times.

\begin{tabular}{lccccc}
\hline Sample no. & Day 1 & Day 4 & Day 7 & Day 10 & Day 13 \\
\hline 1 & 1.5 & 4.5 & 7.3 & 45 & 180 \\
2 & 1.2 & 3.7 & 6.9 & 35 & 130 \\
3 & 1.8 & 3.4 & 5.1 & 38 & 160 \\
4 & 1.0 & 2.8 & 4.6 & 32 & 140 \\
5 & 1.4 & 2.9 & 5.6 & 30 & 70 \\
6 & 1.6 & 2.6 & 4.3 & 33 & 120 \\
7 & 1.2 & 2.8 & 3.8 & 28 & 90 \\
8 & 1.2 & 1.9 & $5.2 \pm 1.3$ & $34.6 \pm 5.3$ & $127.5 \pm 35.3$ \\
Average & $1.3 \pm 0.3$ & $3.0 \pm 0.8$ & & & \\
\hline
\end{tabular}

Table III. Immunophenotype of the 8 samples before and after culture.

\begin{tabular}{|c|c|c|c|c|c|c|c|c|}
\hline \multirow[t]{3}{*}{ Sample no. } & \multicolumn{2}{|c|}{$\mathrm{CD}^{+}$} & \multicolumn{2}{|c|}{$\mathrm{CD}^{+}{ }^{+}$} & \multicolumn{2}{|c|}{$\mathrm{CD}^{+}{ }^{+}$} & \multicolumn{2}{|c|}{$\mathrm{CD}^{+}{ }^{+} \mathrm{CD} 56^{+}$} \\
\hline & \multicolumn{2}{|c|}{ Culture } & \multicolumn{2}{|c|}{ Culture } & \multicolumn{2}{|c|}{ Culture } & \multicolumn{2}{|c|}{ Culture } \\
\hline & Before & After & Before & After & Before & After & Before & After \\
\hline 1 & 45.9 & 90.2 & 31.2 & 42.5 & 41.9 & 58.3 & 1.8 & 38.8 \\
\hline 2 & 54.2 & 90.4 & 29.4 & 41.3 & 40.1 & 57.2 & 1.7 & 32.6 \\
\hline 3 & 51.6 & 89.6 & 33.2 & 39.5 & 38.8 & 52.8 & 1.5 & 36.6 \\
\hline 4 & 49.9 & 91.2 & 27.8 & 32.2 & 45.5 & 57.4 & 1.3 & 32.1 \\
\hline 5 & 56.3 & 88.6 & 30.1 & 47.1 & 36.6 & 46.3 & 1.5 & 28.8 \\
\hline 6 & 48.7 & 92.3 & 28.8 & 35.5 & 45.1 & 51.5 & 2.1 & 27.5 \\
\hline 7 & 53.2 & 91.6 & 28.6 & 34.8 & 38.9 & 45.4 & 1.8 & 36.7 \\
\hline 8 & 47.6 & 87.6 & 30.6 & 46.6 & 43.5 & 53.8 & 1.6 & 31.4 \\
\hline
\end{tabular}

treatment was $>5 \times 10^{9}$. Indomethacin $(25 \mathrm{mg}$, oral) or phenergan (25 mg, intramuscular injection) was administered to the patients $30 \mathrm{~min}$ before treatment to prevent adverse reactions. Saline infusion was administered $2 \mathrm{~h}$ prior to cell transfusion, to ensure smooth fluid pipe flow. In the first year, the treatment of CIK cells should be repeated every 3-6 months, while in the second year treatment can be repeated every 6 months. After that, the CIK therapy should be performed once every year.

Main outcome measures. According to the Cheson criteria, the response criteria were: complete response (CR), partial response (PR), no response (NR) and progression of disease (PD). Primary clinical effect assessment included radiographic images (CT/ECT/PETCT); secondary clinical effect evaluation included T-cell subsets, biochemical, hemogram, bone marrow morphology test and clinical symptoms; and safety assessment included side effects, mortality rate and complications.

Statistical analysis. Data were analyzed using SPSS 13.0 software (SPSS, Chicago, IL, USA). The results were expressed as mean \pm SD. A complete randomized analysis of variance was used to compare differences among groups. $\mathrm{P}<0.05$ was considered to be statistically significant.

\section{Results}

CIK count. The total CIK cell count was $7-18 \times 10^{9}$ (median $\left.12.7 \times 10^{9}\right)$. The absolute count was increased $44-$ to 140-times (median 98) compared to the previous culture. The survival rate evaluated by trypan blue staining was $>90 \%$ (Table II).

CIK phenotype. The average count of the $\mathrm{CD}^{+}, \mathrm{CD}^{+}$, $\mathrm{CD}^{+}$and $\mathrm{CD}^{+}{ }^{+} \mathrm{CD} 56^{+}$cells for the 8 samples was increased to $90.2 \pm 1.6,40.6 \pm 5.5,52.8 \pm 4.9$ and $33.1 \pm 4.0 \%$ on day 13 (Table II), compared to $50.9 \pm 3.5,29.9 \pm 1.7,41.3 \pm 3.2$ and $1.6 \pm 0.2 \%$ before culture. $\mathrm{CD}^{+}{ }^{+} \mathrm{CD} 56^{+}$cells consisted of $2 \%$ of the PBMCs before culture, and the percentage increased to $8.4 \%$ on day 7 , reaching $40-50 \%$ on day 13 . Considering the total proliferation rate of CIK cells, the absolute number for this type of cell was multiplied hundreds of times (Table III).

Measurement of the clinical effect. Radiographic images of the patients included positron emission tomography-computed tomography (PET-CT), emission computed tomography (ECT) or computerized tomography (CT) one month before and after treatment. Metastasis in the liver, spleen, pancreatic tail, abdominal aorta, and bone marrow of one case (SMZL) was eradicated, and the other 2 cases (DLBCL, 
A

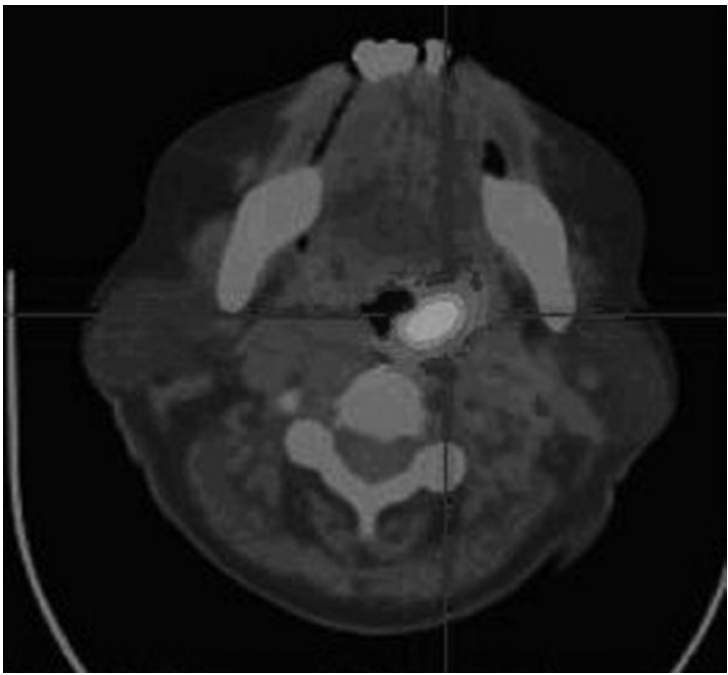

B

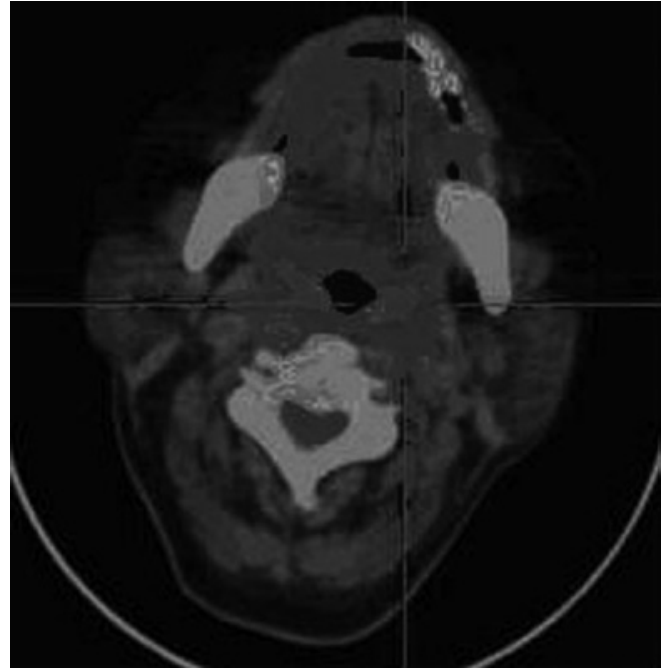

Figure 1. (A) PET-CT image of a patient (male, NHL DLBCL) showing metastasis of the posterior wall of the pharynx prior to treatment. (B) PET-CT image of the same patient (male, NHL DLBCL) showing metastasis of the posterior wall of the pharynx which was totally eradicated following treatment.

A

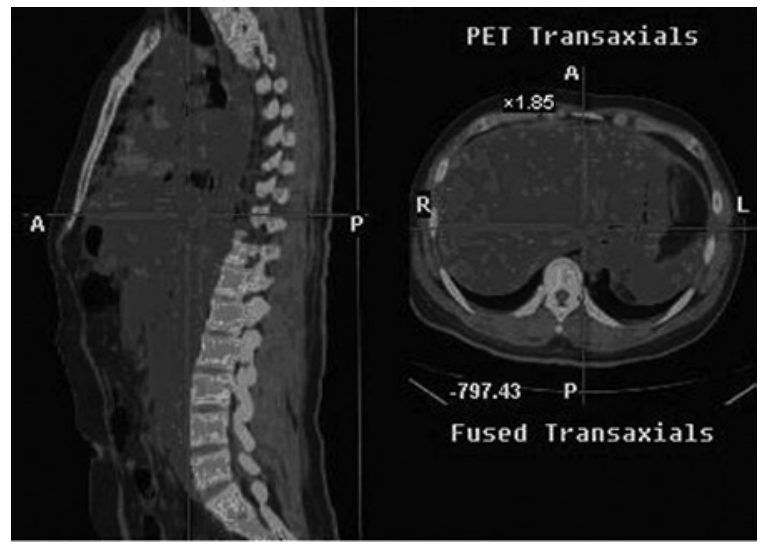

B

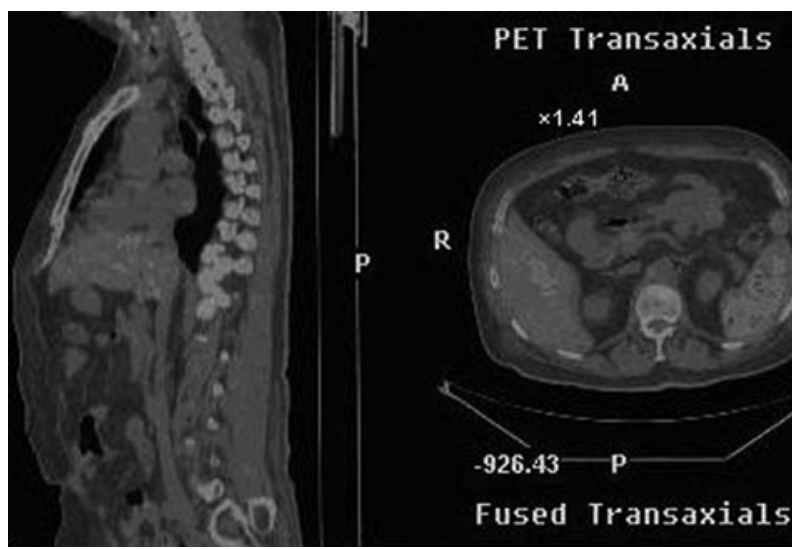

Figure 2. (A) PET-CT image of a patient (male, NHL, SMZL) showing extranodal involvement prior to treatment. (B) PET-CT image of the same patient (male, NHL, SMZL) showing extranodal involvement which was almost eradicated following treatment.

MC) also showed measurable radiographic tumor reduction of the metastases in the lung, liver, and spleen. Other cases also showed tumor reduction (Fig. 1A, the hypermetabolic area prior to CIK treatment as shown in PET-CT; Fig. 1B, following CIK treatment, the hypermetabolic area of the same patient showing measurable radiographic tumor reduction) (Fig. 2A, liver metastasis prior to treatment as shown in PET-CT; Fig. 2B, the metastasis of liver in the same patient following treatment).

T-cell subsets. T-cell subsets were determined when the nucleated cells of the patients were sampled 1 week prior to and after the administration of CIK cell transfusion.

The ratio of $\mathrm{CD}^{+}, \mathrm{CD}^{+}$and $\mathrm{CD}^{+}$cells in the peripheral blood cells in the 8 male patients improved significantly following CIK cell transfusion $(\mathrm{P}<0.05)$ (Table IV).

Bone marrow examination. Patients with bone marrow infiltration had reevaluation of the bone marrow after treatment. The lymphoma cells in the bone marrow of 1 case (SMZL) achieved complete remission compared to $16 \%$ before treat- ment. Other cases also showed reduced levels of lymphoma cells in the bone marrow.

Results of biochemical and hemogram tests of the patients before and after the treatment indicated that the CIK therapy had little toxicity (Table V).

Side effects associated with the CIK treatment. During and after CIK cell transfusion, all of the 8 patients had varying degrees of fever, usually occurring 1-2 $\mathrm{h}$ after the transfusion which lasted for $\sim 8-15 \mathrm{~h}$. The temperatures were $\sim 38^{\circ} \mathrm{C}$. Some patients also developed sustainable low heat one week after treatment. Analgesics were administered. The fever was considered to be the result of metabolic syndrome. One patient developed headache, nausea and vomiting while 2 patients exhibited irritation, which disappeared after treatment withdrawal. None of the patients experienced skin allergies, itching, tachycardia, liver and kidney failure or other adverse reactions.

Complications and symptoms. No incidents of any significant complications following CIK cell transfusion were noted. 
Table IV. The ratio of $\mathrm{CD}^{+}, \mathrm{CD}^{+}$and $\mathrm{CD}^{+}$cells in the peripheral blood cells of the 8 patients.

\begin{tabular}{lcccc}
\hline & $\mathrm{CD} 3^{+}$ & $\mathrm{CD} 4^{+}$ & $\mathrm{CD}^{+}$ & $\mathrm{CD}^{+} / \mathrm{CD}^{+}$ \\
\hline Before treatment & $61.8 \pm 5.6$ & $28.1 \pm 5.2$ & $30.0 \pm 9.5$ & $0.8 \pm 0.5$ \\
After treatment & $69.8 \pm 6.2$ & $32.1 \pm 5.6$ & $32.5 \pm 11.5$ & $1.0 \pm 0.4$ \\
\hline
\end{tabular}

Table V. General conditions of the patients after treatment.

\begin{tabular}{|c|c|c|c|c|c|c|c|c|c|}
\hline $\begin{array}{l}\text { Pt. } \\
\text { no. }\end{array}$ & $\begin{array}{l}\text { Age } \\
\text { (years) }\end{array}$ & Gender & $\begin{array}{l}\text { ECOG } \\
\text { Performance } \\
\text { status }\end{array}$ & $\begin{array}{l}\text { Extra-organ } \\
\text { involvement }\end{array}$ & Tumor & $\begin{array}{c}\text { CIK transfusion } \\
\text { times/cycle } \\
\text { (cell count/cycle } \times 10^{9} \text { ) }\end{array}$ & $\begin{array}{l}\text { Cell count } \\
\quad\left(\times 10^{9}\right)\end{array}$ & Cycles & Response \\
\hline 1 & 22 & M & 0 & None & 0 & $3(6,8,4)$ & 18 & 1 & PR \\
\hline 2 & 26 & M & 0 & $\begin{array}{l}\text { Lung, bone marrow } \\
\text { Thoracic-abdominal wall }\end{array}$ & 0 & $3(5,5,3)$ & 13 & 1 & PR \\
\hline 3 & 36 & M & 0 & Liver, bone marrow & 0 & $3(5,6,5)$ & 16 & 1 & PR \\
\hline 4 & 39 & M & 0 & $\begin{array}{l}\text { Liver, spleen } \\
\text { Thoracic-abdominal wall }\end{array}$ & 0 & $3(3,8,3)$ & 14 & 1 & PR \\
\hline 5 & 41 & M & 0 & - & 0 & $4(2,8,1,2)$ & 13 & 1 & CR \\
\hline 6 & 45 & M & 0 & - & 0 & $3(3,3,1)$ & 7 & 1 & PR \\
\hline 7 & 55 & M & 2 & $\begin{array}{l}\text { Bone marrow } \\
\text { Thoracic-abdominal wall }\end{array}$ & 0 & $4(3,3,4,2)$ & 12 & 1 & PR \\
\hline 8 & 65 & M & 1 & $\begin{array}{l}\text { Pancreas, liver } \\
\text { Bone marrow }\end{array}$ & 0 & $2(6,3)$ & 9 & 1 & PR \\
\hline
\end{tabular}

M, male; CR, complete response; PR, partial response.

Most of the patients had improved physical conditions, such as sleep, physical strength and appetite. No delayed side effects occurred.

\section{Discussion}

Refractory lymphoma is generally defined as treatment ineffective after at least 2 cycles of chemotherapy, or relapse shortly after withdrawal. Although autologous hematopoietic cell transplantation has proven to be an effective therapy for patients with refractory and relapsed malignant lymphoma, feasibility and affordability limit its widespread application. Therefore, applicable and effective strategies should be developed. A variety of treatment strategies have been explored, including cytokines, activated NK cells and monoclonal antibodies.

In the present study, CIK cells were cultured using PBMCs collected by a blood cell separator from 8 patients with refractory lymphoma in vitro. We previously demonstrated that CIK cells developed in this way possess the ability to achieve a high proliferation rate, and the immunophenotype of the cells indicates strong anti-tumor activities. The time course for the addition of IFN- $\gamma$ was found to be crucial in enhancing the cytotoxic activity. The addition of IL-2 following that of IFN- $\gamma$ led to an increase in cytotoxicity. Furthermore, the combination of IFN- $\gamma$ and anti-CD3 enhances the proliferative effect of the anti-CD3 treatment with an increase in cytotoxicity by IFN- $\gamma$.
This is the first study to evaluate the clinical efficacy of CIK cell treatment on patients with refractory lymphoma. The anti-tumor effect of CIK cells was shown mainly for lymphoma cell lines and leukemic blasts either in vitro or in vivo $(2,10,11)$. The mechanism of CIK anti-tumor activity mainly involves the following procedures: $\mathrm{CD} 3{ }^{+} \mathrm{CD} 56^{+}$cells release large amounts of cytotoxic granules that dissolve target cells. In addition, CIK cells secrete a variety of cellactivating factors, such as IFN- $\gamma$, TNF and IL-2, which not only directly inhibit tumor growth, but also regulate the body's immune system response to the indirect killing of tumor cells. CIK cells also induce tumor cell apoptosis. Their cytotoxic effect is mediated by a perforin/granzyme-dependent mechanism, and targeted tumor recognition capacity appears to be partly mediated by NKG2D, an activating receptor on NK cells, and the adhesion receptor leukocyte function-associated antigen-1 (LFA-1) $(12,13)$. Recently, it has been reported that CIK cells use tumor necrosis factor-related apoptosis-inducing ligand (TRAIL) to activate caspase-3, which is responsible for apoptosis (6).

We assessed T-cell subsets before and after treatment, which reflected the immune function of the patients. The results showed that CIK cell therapy significantly improved $\mathrm{CD}^{+}, \mathrm{CD}^{+}{ }^{+}, \mathrm{CD}^{+}{ }^{+} \mathrm{CD}^{+}{ }^{+}$T-cell counts, which is crucial for malignant lymphoma patients whose immune functions are extremely low after routine treatment. In addition, patients with loss of appetite and sleep, showed relief of these symptoms following treatment, showing that patient quality of life 
is significantly improved. Furthermore, no serious side effects occurred after CIK treatment, indicating that CIK therapy is safe for clinical application although larger population cohorts should be investigated. To gain a better understanding of the long-term efficacy of CIK therapy, follow-up of these patients is required.

In conclusion, CIK cells are readily isolated and expanded from peripheral blood mononuclear cells of patients with malignant lymphoma. Due to the low level of side effects and effective anti-tumor activity, CIK therapy may be a novel option in the treatment of patients with refractory and relapsed malignant lymphoma.

\section{References}

1. Schmidt-Wolf IG, Negrin RS, Kiem HP, et al: Use of a SCID mouse/human lymphoma model to evaluate cytokine-induced killer cells with potent antitumor cell activity. Exp Med 174: 139-149, 1999.

2. Linn YC and Hui KM: Cytokine-induced killer cells: NK-like $\mathrm{T}$ cells with cytotolytic specificity against leukemia. Leuk Lymphoma 44: 1457-1462, 2003.

3. Leemhuis T, Wells S, Scheffold C, et al: A phase I trial of autologous cytokine-induced killer cells for the treatment of relapsed Hodgkin disease and non-Hodgkin lymphoma. Biol Blood Marrow Transplant 11: 181-187, 2005.

4. Chan JK, Hamilton CA, Cheung MK, et al: Enhanced killing of primary ovarian cancer by retargeting autologous cytokineinduced killer cells with bispecific antibodies: a preclinical study. Clin Cancer Res 12: 1859-1867, 2006.

5. Shi M, Zhang B, Tang ZR, et al: Autologous cytokine-induced killer cell therapy in clinical trial phase I is safe in patients with primary hepatocellular carcinoma. Clin Trial 10: 1146-1151, 2004.
6. Kuci S, Rettinger E, Voss B, et al: Efficient lysis of rhabdomyosarcoma cells by cytokine-induced killer cells: implications for adoptive immunotherapy after allogeneic stem cell transplantation. Haematologica 95: 1579-1586, 2010.

7. Sangiolo D, Mesiano G, Carnevale SF, et al: Cytokine induced killer cells as adoptive immunotherapy strategy to augment graft versus tumor after hematopoietic cell transplantation. Expert Opin Biol Ther 9: 831-840, 2009.

8. Nishimura R, Baker J, Beilhack A, et al: In vivo trafficking and survival of cytokine-induced killer cells resulting in minimal GVHD with retention of anti-tumor activity. Blood 112: 2563-2574, 2008.

9. Sangiolo D, Martinuzzi E, Todorovic M, et al: Alloreactivity and anti-tumor activity segregate within two distinct subsets of cytokine-induced killer (CIK) cells: implications for their infusion across major HLA barriers. Inter Immunol 20: 841-848, 2008.

10. Alvarnas JC, Linn YC, Hope EG, et al: Expansion of cytotoxic $\mathrm{CD}^{+}{ }^{+} \mathrm{CD} 56^{+}$cells from peripheral blood progenitor cells of patients undergoing autologous hematopoietic cell transplantation. Biol Blood Marrow Transplant 7: 216-222, 2001.

11. Kornacker M, Moldenhauer G, Herbst M, et al: Cytokine-induced killer cells against autologous CLL: direct cytotoxic effects and induction of immune accessory molecules by interferon-gamma. Int J Cancer 119: 1377-1382, 2006.

12. Mehta BA, Schmidt-Wolf IG, Weissman IL, et al: Two pathways of exocytosis of cytoplasmic granule contents and target cell killing by cytokine-induced $\mathrm{CD} 3{ }^{+} \mathrm{CD} 56^{+}$killer cells. Blood 86: 3493-3499, 1995

13. Verneris MR, Karami M, Baker J, et al: Role of NKG2D signaling in the cytotoxicity of activated and expanded CD8 ${ }^{+}$ T cells. Blood 103: 3065-3072, 2004. 